\title{
Chemical Modification on Woven Jute and Nonwoven Wet-Laid Glass Fiber Sheet Reinforced Poly-( $\varepsilon$-Caprolactone) Composites
}

\author{
Mohammad Muzammel Hossen* (), Mohammad Obaidur Rahman \\ BGMEA University of Fashion \& Technology (BUFT), Dhaka, Bangladesh \\ Email: *muzammel.ananda@gmail.com
}

How to cite this paper: Hossen, M.M. and Rahman, M.O. (2021) Chemical Modification on Woven Jute and Nonwoven WetLaid Glass Fiber Sheet Reinforced Poly- $(\varepsilon$ Caprolactone) Composites. Open Journal of Composite Materials, 11, 63-81. https://doi.org/10.4236/ojcm.2021.114006

Received: July 7, 2021

Accepted: August 29, 2021

Published: September 1, 2021

Copyright (c) 2021 by author(s) and Scientific Research Publishing Inc. This work is licensed under the Creative Commons Attribution International License (CC BY 4.0).

http://creativecommons.org/licenses/by/4.0/

\begin{abstract}
High-moisture regains nature of cellulosic fibers considered one of the critical drawbacks for jute-based applications. To minimize this by developing better interfacial adhesion, a hydrophobic nonwoven wet-laid glass fiber sheet used the woven jute fabric in this experiment. For this purpose, woven jute fabric was categorized into untreated, silane, alkali, and alkali-silane combined treatment then compounded with the solution of polycaprolactone (PCL). Fabrication of composites performed the following sandwich method based on different hot-pressing time with temperature for detecting a prominent fabrication parameter. Surface treated jute fibers characterized using FTIR spectroscopy. Hence, the mechanical and thermal properties of composites were investigated to find the consequence of chemical treatments into woven jute fabric. Alkali-silane combined chemical treatments resulting in improved $48.38 \%$ of tensile strength over untreated optimized composites. Scanning electron microscope (SEM) used for displaying interfacial adhesion between fiber and polymer matrix. Besides, further investigation demonstrated due to the combined chemical treatment of alkali-silane optimized composites significantly enhanced the thermogravimetric (TGA) stability in contrast to other composites.
\end{abstract}

\section{Keywords}

Woven Jute Fabric, Polycaprolactone, Compression Molding, Surface Modification, Mechanical Properties

\section{Introduction}

Composite is a substance that's formed using mixing two or more verity of substances in such a way that the outcome substances delivered with properties su- 
perior contrast to ordinary ones. Polymer matrix-based reinforces composite got comparatively more attraction compared to ceramic and metal matrix as well as in the area of textile and material research. The exceptional resistance of glass fibers into the ecological assault produced glass-fiber-reinforced polymers more appealing among food and chemical sectors as well as due to low elongation at break, better stiffness and strength with preferable properties turned PCL significant biopolymer contributor in the area of tissue engineering, medical surgery, aerospace, construction industry, automobile, environmental engineering application as well as unremittingly opening new industrial possibilities are broadening day by day [1] [2] [3] [4] [5]. Ordinary jute can be utilized for elementary and non-invasive industrial textile items, whether expected property achieved throughout proper modification, as well as the industry can be capable of offering professional and environmentally friendly products within a reasonable price. Jute has a good enough mechanical property of high specific mechanical strength, good moisture regain (13.75\%) and $100 \%$ degradable, renewable resources, ease of access, lower-cost, highly breathable, and lower contamination emission to nature [6] [7]. These factors make jute fiber along with coir, flax, sisal, pineapple, ramie, hemp, and kenaf a high point of interest for researchers for using as a reinforcing material [8]-[15].

As a second, most used organic fiber jute will be an outstanding substitute, whereas prospective high specific strength, nonrenewable resources, and a comparatively lower price is an important issue [16]. On the other hand, glass fiber gained enormous attention from the past century to the researchers in compared to other synthetic fiber benefits including significant stiffness, high heat, corrosive and impact resistance, comparatively lower price and simplicity of setup, better processability, relatively better immunity to environmental substances and fatigue [17].

For this reason, a substitute for concrete, wood, and metal materials with glass fiber used a broad array utilizing in fabricating different types of composites such as insulation, heat and corrosion-resistant application, and noise reduction [18]. K, Jarukumjorn et al. [19] investigated the tensile strength and bending strength improved after using glass fiber as reinforcement in the sisal-PP composite without influencing tensile and bending modulus as well as significant improvement exhibited in the thermal degradation along with moisture absorption properties of the composite. Manually chopped short length jute with glass fiber reinforced hybrid PET composites exhibit significant improvements in mechanical property due to affecting heap order [20]. R, Velmurugan et al. [21] studied adding glass fiber with palmyra hybrid composite improves the mechanical property, and adding extra glass fiber exhibited further improvements in successive rate. Huq, Tanzina, et al. [22] performed a comparative interfacial property evaluation of jute glass-fiber-reinforced PET composite results exhibited glass matt-pet composites comparatively better mechanical (Tensile, flexural and water absorption) properties compared to other composites in the experimental group. M, Boopalan, et al. [23] executed a comparative investigation 
in jute-sisal reinforced PLA biocomposites where jute reinforced PLA biocomposites outcome revealed significantly improved mechanical properties than sisal. T. Munikenche Gowda et al. [24] analyzed the mechanical property test of jute-glass-fiber reinforced polyester Figured even though mechanical properties of jute/polyester composites tend not to own matrix and strengths as large as those of other traditional composites, they could process much better advantages than timber composites and several plastics. Besides, they have some drawbacks, too; weak interfacial adhesion between natural fiber and thermoplastic is the major problem that can overcome by treating the surface of fiber using different chemical processing [25].

Alkali treatment washes out the impurities of fiber and increases the interfacial bonding between the fiber and thermoplastic polymer as well as micro-fibril rearrange of cellulosic content and lignin dissolving of highly hydrophobic content of fiber [26] [27]. After investigating previous studies, soaking jute fibers fiber in a solution of silane coupling agent for surface treatment resulting in better mechanical properties with strong interfacial adhesion also exhibited slightly improved outcomes in thermal stability over untreated even more then alkali-treated bio composites broadly contemplated in [28] [29]. Gassan et al. performed an investigation in epoxy with 3-glycidoxypropyltrimethoxysilane (KH560) treated jute and concluded with a result of enhanced $100 \%$ of dynamic modulus over untreated experimental composites. Wang, Xue, et al. [30] studied woven jute with silane coupling agent (KH560) modified epoxy laminated composite trend to better adhesion between fiber epoxy with enhanced crystallinity and thermal stability, 10 times better silicon grafted in jute fiber exhibit upon EDS observation as well as tensile strength (42\%), tensile modulus (39\%), bending strength (49\%) and flexural modulus (51\%) enhanced due to silane treatment compared to untreated woven jute which is comparatively better than few wood-based composite application. Having $\mathrm{OH}$ and amine (Primary $\mathrm{NH}_{2} \mathrm{Sec}-$ ondary $\mathrm{NH}_{4}$ ) groups, the silane coupling agent can help to set up a bond between the fibers and polycaprolactone (PCL). Debeli et al. [31] performed comparative investigation and outcome exhibited natural fiber reinforced PLA biocomposites and concluded with fiber, which surfaces treated with a silane coupling agent and alkali exhibited noticeable outstanding results in the area of tensile strength and modulus, flexural strength and impact strength as well as enhanced burial degradation process demonstrated over untreated bio-composites. Both jute and glass fiber have a significant property to develop advanced products as well as further research needed.

However, only a few researchers investigated and fabricated woven jute, and wet-laid glass fiber sheet reinforced PCL composites using a hot-pressing method. In this research paper, woven jute fabric surface chemically modified with a silane coupling agent, alkali and alkali-silane combined treatments along with commercial untreated woven jute fabric for the comparative purpose. A design was containing eight optimized samples prepared throughout the hot-pressing 
method according to different hot-pressing temperatures, time and pressure to find out preeminent processing conditions and effects of different chemical treatments in optimized woven jute and glass fiber reinforced PCL composite properties.

\section{Experimental}

\subsection{Materials and Method}

In this experiment, polycaprolactone (PCL) granules were used as a matrix with dichloromethane (DCM) as a solvent for dissolving PCL. For fiber surface treatments, alkali (sodium hydroxide- $\mathrm{NaOH} \geq 98 \%$ ), and silane coupling agent (3-glycidoxypropyltrimethoxysilane-KH560 $\geq 98 \%$ ) with a molecular weight of 236.34 obtained from Hangzhou mi ke chemical instrument co. Ltd, Hangzhou, China. Besides, woven jute fabric was collected from the local market of Narsingdi, Dhaka, Bangladesh-1200, then cut manually $20 \times 20 \mathrm{~cm} \&$ specimens comprising $40 \mathrm{wt} \%$ jute fibers were fabricated using the hot-pressing method. Nonwoven wet-laid glass fiber sheet obtained from Xinxiang filter material Co. Ltd., China, was use as a reinforcement of PCL with woven jute fabric. Other significant parameters of jute fiber, glass fiber, and PCL matrix are presented in Table 1.

\subsection{Fiber Treatments and Composite Fabrication}

An amount of $7 \%(7 \mathrm{~g} / 100 \mathrm{~mL}$ water $) \mathrm{NaOH}$ solution was prepared. Woven jute fabric $(20 \times 20 \mathrm{~cm})$ dipped in a solution of $7 \% \mathrm{NaOH}$ and dried in a woven (Shanghai Hasuc Tools Fabricate Co. Ltd., model: DHG-90538) at $80^{\circ} \mathrm{C}$ temperature for 60 minutes. After completing the drying process, treated woven jute fabric kept 9 hours at room temperature. Again, jute fabric is saturated in a solution of $\mathrm{KH} 560$ (7 g/100mL water) and kept for a maximum of 10 hours at room temperature. Besides, woven jute fibers were dipped in a solution of $7 \% \mathrm{NaOH}$ and $7 \% \mathrm{KH} 560 / 100 \mathrm{~mL}$ water for comparison purposes. Afterward, both treated jute fibers had rinsed with regular water using acetic acid till surplus alkali $(\mathrm{NaOH})$ and silane (KH560) were removed away and maintained a $\mathrm{pH}$ value of 5 for both chemically treated fiber due to enhancing hydrolysis process. Subsequently, completion of the treatment process, both treated fibers dried in woven at $80^{\circ} \mathrm{C}$ for almost 5 hours separately for reduced absorbed moisture content and eliminate unwanted void space during the fabrication of composites.

Table 1. Detailed mechanical properties of jute, glass fiber sheet, and polycaprolactone.

\begin{tabular}{cccc}
\hline Properties & Jute & Glass fiber & PCL \\
\hline Density $\left(\mathrm{g} / \mathrm{cm}^{3}\right)$ & 1.3 & $2.5 \pm 0.1$ & 1.1 \\
Molecular weight & & & 38,000 \\
Melting temp. $\left({ }^{\circ} \mathrm{C}\right)$ & $650 \pm 15$ & $59-64$ \\
Thickness $(\mathrm{mm})$ & $\leq 1.2$ & \\
Glass transition temp. $\left({ }^{\circ} \mathrm{C}\right)$ & & -64 \\
\hline
\end{tabular}


Furthermore, silane comprises an epoxy group that functions as an organofunctional silane trend to enhance interfacial adhesion within fibers and reinforced matrix - a detailed three-stage chemical reaction mechanism of KH-560, and $\mathrm{NaOH}$ with woven jute fabric representing in Figure 1. As demonstrated in Scheme 1, silane reacts with water to form silanol and alcohol. In Scheme 2, a stable covalent bond was created using reaction with a fibers hydroxyl group and silanol [32]. As demonstrated in Scheme 3, methyl functional group of silanes would react with the matrix hydroxyl group when they reinforced together; thus, an enhanced bond formed within PCL matrix and silane coupling acid resulting enhanced fiber-matrix adhesion. Natural cellulose is a monoclinic crystalline lattice of cellulose-I structure. This structure converted into Na-cellulose-I after reacting with alkali which is exhibiting in Scheme 4. Besides, this structure changed to cellulose-II due to washing with distilled water [1].

The treated woven jute fabrics were exposed to open air for five days, then a solution of PCL (1:3 ratio for PCL: DCM) took in a glass beaker and mixed using electric stirrer almost 90 minutes until PCL granules dissolve properly within DCM solvent. Woven jute fabric wetted with PCL solution manually and dried 2 $\mathrm{h}$ at room temperature before going through the fabrication process of composites, A design containing eight samples followed closely, as well as a hot-pressing process, was selected and intended to detect a compatible condition for assembling composite based on different hot-pressing temperatures of $155^{\circ} \mathrm{C}$ and $165^{\circ} \mathrm{C}$, time 9-minute heating with 6-minute curing and pressure of $7 \mathrm{MPa}$ respectively. Moreover, a detailed schematic fabrication process of woven jute and glass fiber reinforced PCL composite is presented in Figure 2.
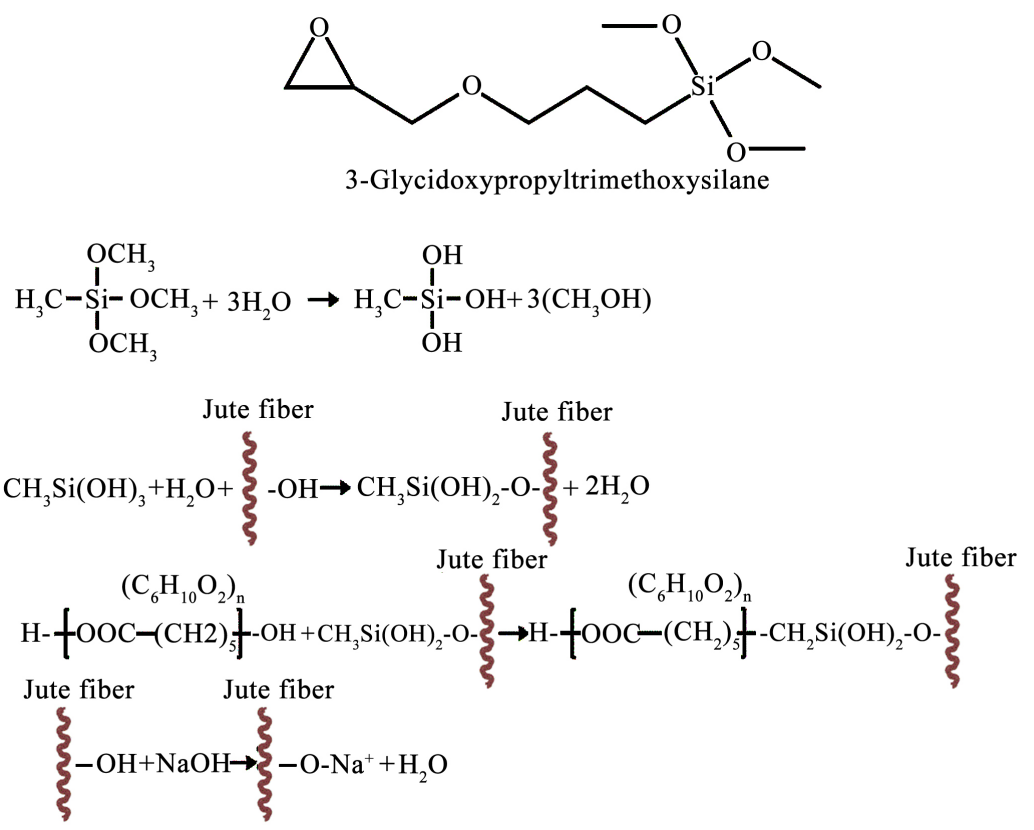

Figure 1. Scheme (1) representing the chemical structure of silane coupling agent (KH-560), (2), (3) representing the reaction of KH560 with woven jute fabric (4) representing the chemical reaction of $\mathrm{NaOH}$ with woven jute fabric [26] [28]. 


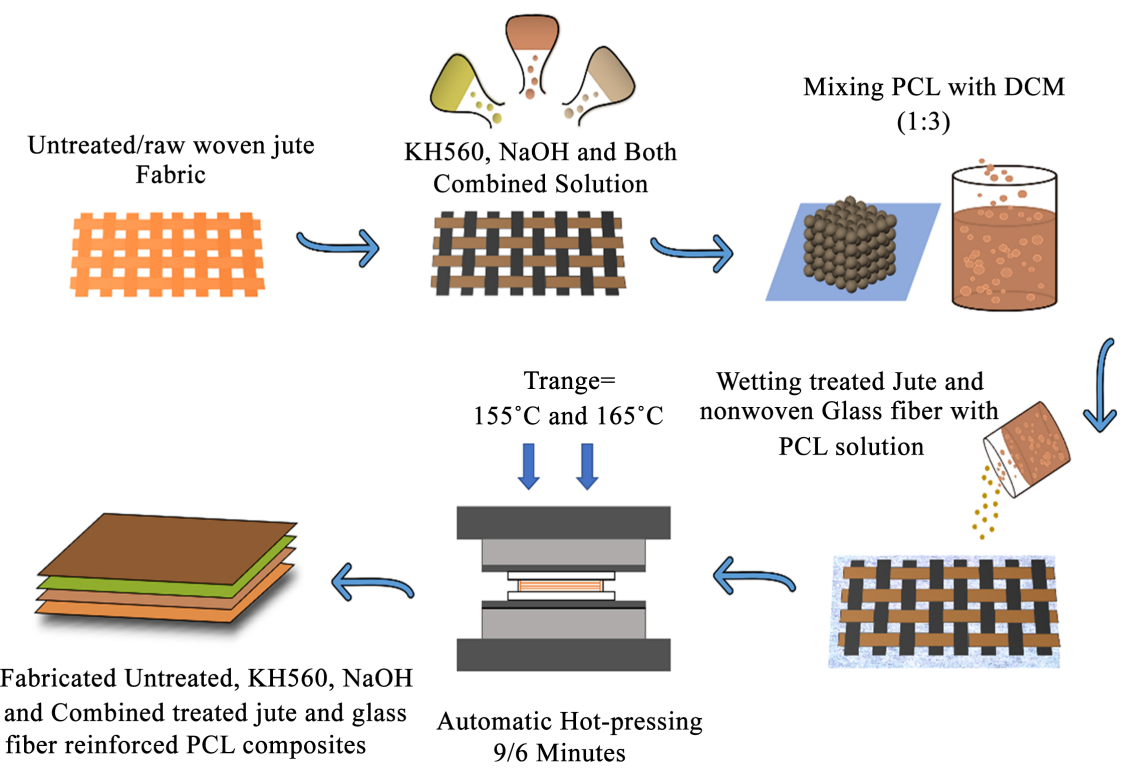

Figure 2. The schematic fabrication process of woven jute fabric and glass fiber reinforced PCL composites.

\section{Characterization}

\subsection{Fourier Transform Infrared (FTIR)}

Fourier transform infrared (FTIR) was performed to observe the spectra changes and surface functional groups due to chemical treatments. Dried $2 \mathrm{mg}$ powder of jute fiber mixed with $\mathrm{KBr}$ further compounded into a fine powder using mortar and pestle then compressed. Jute fiber both treated and untreated surface chemistry analyzed using (Nicolet, Model: iS50 FT-IR) within a range of $500-4000 \mathrm{~cm}^{-1}$.

\subsection{Tensile Strength and Modulus}

Tensile strength test completed and documented data at room temperature of $20^{\circ} \mathrm{C}$ and $65 \%$ relative humidity employing a computer-controlled Instron tester (Model: 5943, Instron Shanghai Ltd.) The entire testing was conducted following the standard of GB/T1447-2005 with a loading speed rate of $5 \mathrm{~mm} / \mathrm{min}$ [33]. For tensile strength specimen tested and recorded data carefully.

\subsection{Water Absorption}

WA measured following ASTM D570 standard, and each of the calculations \& outcomes was recorded carefully. Before immersion, all prepared optimized samples dried at $60^{\circ} \mathrm{C}$ for 5 hours. Subsequently, the WA test has been sustained to 180 hours. Each of the outcomes listed carefully within the specified time using Yueping automatic electrical balance (capacity of Min: 10 milligrams Max: 100 gm, Model: FA1004B, Shanghai Yueping Scientific Tool Co., Ltd., China) in room temperature.

$$
M_{t}(\%)=\frac{M t-M_{1}}{M_{1}} \times 100 \quad[34]
$$


where, $M t$ stands for sample weight, $t$ for immersion time, and $M_{1}$ is initial dry sample weight.

\subsection{Thickness Swelling}

Thickness swelling (TS) was conducted according to ASTM, D570 standard. Prepared specimens immersed in distilled water [35] and recorded data in room temperature at $20^{\circ} \mathrm{C}$ and $65 \%$ humidity using a thickness tester (Model: FY144, Wenzhou Fang yuan Instrument Co. Ltd., China). In total, five times tested every optimized sample and averaged to get the accurate data.

\subsection{Thermogravimetric Analysis of Optimized Composites}

Thermogravimetric or thermal decomposition analysis (TGA) of woven jute and glass fiber reinforced PCL composites studied to observe the thermal degradation behavior of treated and untreated composites. Whereas the sample weight was 3 to $8 \mathrm{mg}$, temperature range, and the rate was respectively $30-600\left({ }^{\circ} \mathrm{C}\right)$ and $20^{\circ} \mathrm{C} / \mathrm{min}^{-1}$ using (NETZSCH Model: TG209 F1 Libra; Germany).

\subsection{Morphology Analysis of Optimized Composites}

The morphological composition of woven jute and glass fiber reinforced PCL composites was studied to see the interfacial adhesion between fiber and matrix using an SEM (Scanning Electron Microscopes JSM-5610LV from JEOL, Japan) after being coated with gold (JFC-1600 fine auto coater from JEOL, Japan). The SEM specimens received from fracture during tensile strength test.

\section{Results \& Discussion}

\subsection{Characterization of Treated and Untreated Composites Surface Chemistry}

The consequences of silane and alkali treatments significantly enhanced the mechanical properties of woven jute, and glass fibers reinforced PCL composites over untreated composites distinctly observed from outcomes of Figure 5. The outcomes of FTIR spectroscopy due to chemical treatments in woven jute fabric are exhibited in Figure 3.

The treated and untreated composites revealed a broad and powerful vibration spectrum in $3435 \mathrm{~cm}^{-1}, 3440 \mathrm{~cm}^{-1}, 3439 \mathrm{~cm}^{-1}$, and $3434 \mathrm{~cm}^{-1}$ for untreated, silane, alkali, and combined-treated jute suggesting $\mathrm{O}-\mathrm{H}$ stretching vibration due to cellulose [36]. In $2950 \mathrm{~cm}^{-1}$ and $2871 \mathrm{~cm}^{-1}$ vibration peak detected for methyl and methylene group (cellulose and hemicellulose) revealed by $\mathrm{C}-\mathrm{H}$ stretching that transfer to $2917 \mathrm{~cm}^{-1}, 2865 \mathrm{~cm}^{-1}$ for silane in alkali $2942 \mathrm{~cm}^{-1}, 2865 \mathrm{~cm}^{-1}$ and combined treated jute which is slightly minimized and transferred to 2915 $\mathrm{cm}^{-1}$ and $2853 \mathrm{~cm}^{-1}$ respectively [37]. The robust peak is showing in untreated jute at $1730 \mathrm{~cm}^{-1}$ corresponding vibration stretching from the carboxylic acid $(\mathrm{C}=\mathrm{O})$ and ester attributing of having hemicellulose content in jute fiber [38] which due to structural change shifted silane $1743 \mathrm{~cm}^{-1}$ and alkali $1733 \mathrm{~cm}^{-1}$ 


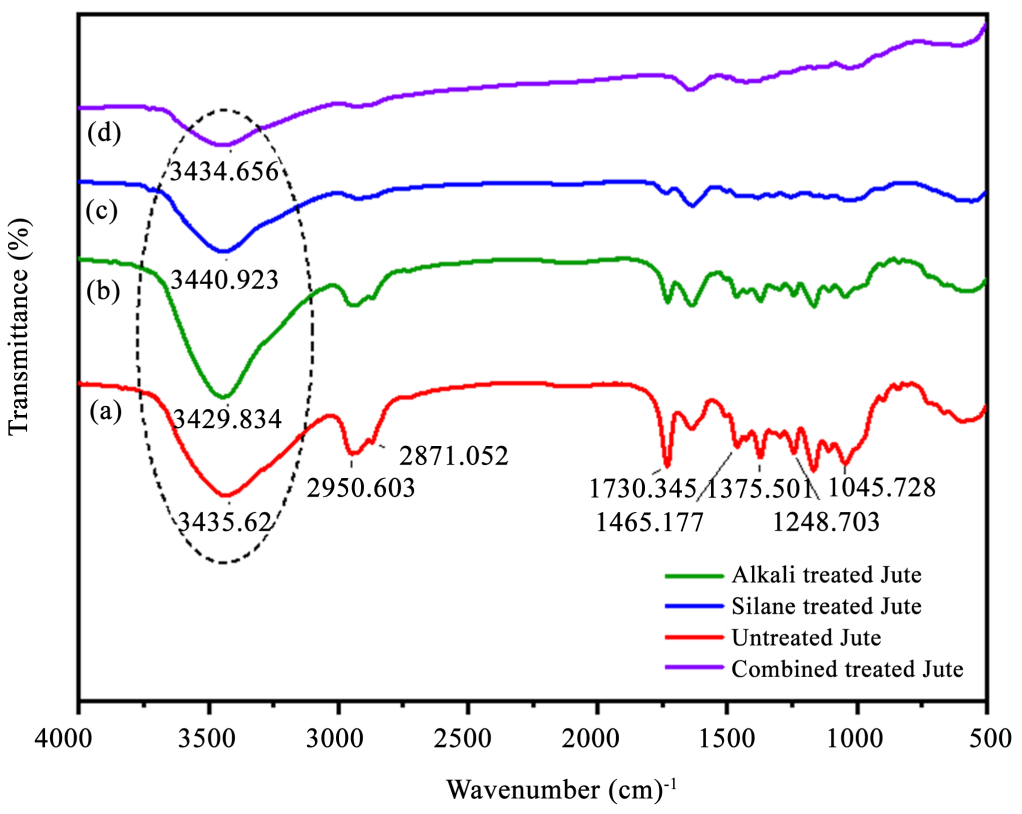

Figure 3. FTIR spectroscopy of untreated and treated woven jute and glass fiber reinforced PCL composites.

after chemical treatment. Besides, absorption spectra detected at $1465 \mathrm{~cm}^{-1}$ represents $-\mathrm{CH}_{3}$ bond, peaks presenting in $1375 \mathrm{~cm}^{-1}$ and $1248 \mathrm{~cm}^{-1}$, respectively attributing of lignin $\mathrm{C}-\mathrm{H}$ stretching vibration. These peaks minimized in the treated spectra are an indication of lignin removed after chemical treatment [39]. Furthermore, peaks presenting in untreated jute fiber spectra around $1045 \mathrm{~cm}^{-1}$ representing $\mathrm{C}-\mathrm{O}-\mathrm{C}, \mathrm{O}-\mathrm{H}$ and $\mathrm{C}-\mathrm{O}$ stretching of celluloses and hemicellulose [3] [38].

As demonstrated in Figure 4, small spectra in combined treated jute, indicating near $1000 \mathrm{~cm}^{-1}$ due to asymmetric stretching vibration of Si-O-Si or cellulose-O-Si bonds because of possible reaction among cellulose hydroxyl and hydrolyze of silane [40] [41]. $\mathrm{KH} 560$ holds $\mathrm{OH}$ and $\mathrm{NH}_{2}$ group, which creates a connection involving treated fibers with the matrix as well as occupying polar and non-polar groups supplied maximum pressure and heat significantly toward treated fiber throughout composites fabrication [31]. Also, the effect of chemical treatments on woven jute fabric surface is presented in Figure 4.

\subsection{Tensile Strength}

Figure 5 exhibiting tensile strength of woven jute \& glass fiber reinforced PCL composites for various preparing conditions (preparing conditions 1, 2, 3, $4, \ldots 8$ ), as displayed in Table 2 .

Proper working parameters are incredibly potential to provide outstanding results together with the essential chemical and physical attributes required. The chemical treatment effect observed from the outcomes of composite mechanical properties. As demonstrating, combined-treated composite sample $\mathrm{C}_{2}$ (7\% of $\mathrm{NaOH}$ and $\mathrm{KH} 560$ with $165^{\circ} \mathrm{C}$ temperature and $7 \mathrm{MPa}$ Pressure) exhibiting a 


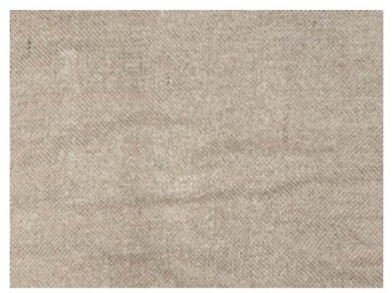

(a)

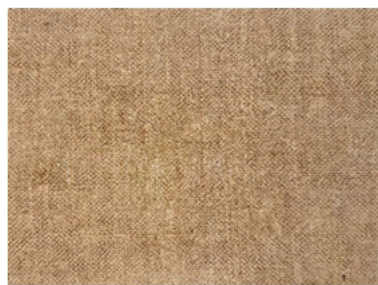

(c)

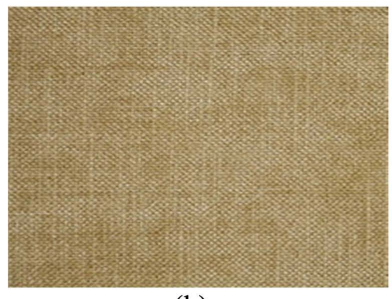

(b)

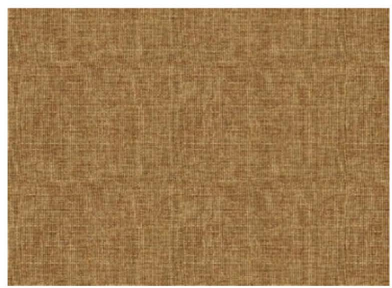

(d)

Figure 4. The photographic spectacle of (a) Raw/untreated; (b) Treated with alkali; (c) Silane; (d) Alkali-silane combined treated woven jute fabric.

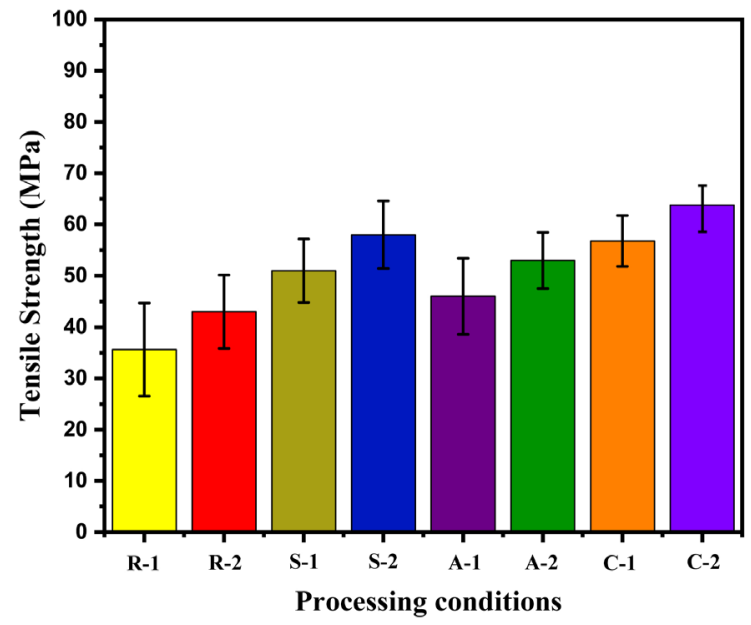

Figure 5. Tensile strength of woven jute and nonwoven glass fiber reinforced PCL composites.

Table 2. Detailed process and parameter for fabricating woven jute and glass fiber reinforced PCL composites.

\begin{tabular}{cccccc}
\hline Serial & $\begin{array}{c}\text { Chemical } \\
\text { treatments }\end{array}$ & $\begin{array}{c}\text { Sample } \\
\text { designation }\end{array}$ & $\begin{array}{c}\text { Temperature } \\
\left({ }^{\circ} \mathrm{C}\right)\end{array}$ & $\begin{array}{c}\text { Heating/curing } \\
\text { time }(\mathrm{min})\end{array}$ & $\begin{array}{c}\text { Pressure } \\
(\mathrm{MPa})\end{array}$ \\
\hline 1 & Untreated & $\mathrm{R}_{1}$ & 155 & $9 / 6$ & 7 \\
2 & Untreated & $\mathrm{R}_{2}$ & 165 & $9 / 6$ & 7 \\
3 & $\mathrm{KH} 560$ & $\mathrm{~S}_{1}$ & 155 & $9 / 6$ & 7 \\
4 & $\mathrm{KH} 560$ & $\mathrm{~S}_{2}$ & 165 & $9 / 6$ & 7 \\
5 & $\mathrm{NaOH}$ & $\mathrm{A}_{1}$ & 155 & $9 / 6$ & 7 \\
6 & $\mathrm{NaOH}$ & $\mathrm{A}_{2}$ & 165 & $9 / 6$ & 7 \\
7 & $\mathrm{KH} 560+\mathrm{NaOH}$ & $\mathrm{C}_{1}$ & 155 & $9 / 6$ & 7 \\
8 & $\mathrm{KH} 560+\mathrm{NaOH}$ & $\mathrm{C}_{2}$ & 165 & $9 / 6$ & 7 \\
\hline
\end{tabular}


substantial maximum effect over other composites. The fiber mass volume ratio has a vital role in keep and dispersing by PCL construction via an external heat and load supplied on composites [2]. Furthermore, 9 minutes of hot-pressing with 6 min curing considered appropriate requirements for this experimental group to get extraordinary results. Mechanical properties of composite mostly depend on interfacial adhesion between fiber and matrix as well as individual fiber and matrix strength and modulus [1]. Alkali and silane combined treatment occur potential physical and chemical modification into fiber surface resulting in better interfacial bonding with enhanced tensile strength and modulus over untreated fiber. Because insufficient heat transfer failed to spread PCL properly through jute fabric leads to improper wettability to the surface of jute fiber as well as the interface of glass fiber, causing comparatively weak interfacial adhesion between untreated jute fiber and PCL consequences sample $\mathrm{R}_{1}$ displaying the lowest results in the experimental group. Combined treatment in nonwoven jute fiber matt significantly reduces jute fiber stiffness with increased fiber surface roughness develops better interfacial adhesion [28] within jute fiber and PCL, resulting in exhibiting better tensile strength, which is almost $48.37 \%$ and $32.04 \%$ higher compared to untreated composites tensile strength.

\subsection{Water Absorption (WA)}

WA test was performed to observe the amount of moisture absorption of optimized composites $\left(\mathrm{R}_{2}, \mathrm{~A}_{2}, \mathrm{~S}_{2}\right.$, and $\left.\mathrm{C}_{2}\right)$ after immersion in distilled water for a specific period, and the result is displayed in Figure 6.

Figure 6 exhibiting the effect variation due to consuming water in air-filled voids, and pores contribute to up-taking more water and increase the weight of composites. Moisture absorption of composite influenced by cellulosic fiber

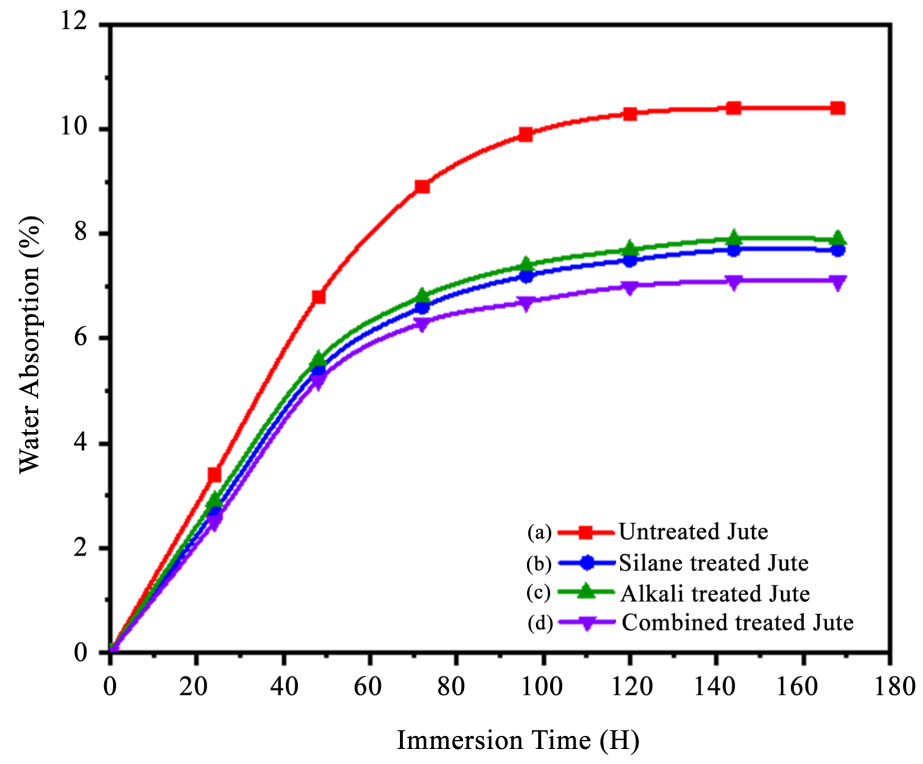

Figure 6. Water absorption behavior of treated and untreated woven jute and glass fiber reinforced PCL optimized composites. 
content, matrix stiffness, hardness, void, or empty hole in composite, humidity, and temperature [42]. As demonstrated, untreated jute and glass fiber reinforced PCL composite optimized sample $\mathrm{R}_{2}$ consumed more water in the air-filled void and pores basically created during fabrication of composites over treated composites, which is $31.73 \%$ more than silane treated optimized sample $\mathrm{S}_{2}$. That is an indication of changing in dimensional stability of the cellulose-based composites. The WA behavior of composites determined by the capability of their fiber to consume water or moisture due to the existence of hydroxyl groups that mainly responsible for WA throughout the creation of hydrogen $(\mathrm{H})$ bonding. The higher the moisture content of any organic fiber, higher alteration in the mechanical and physical characteristics of the composites, resulting in lower adhesion between reinforced matrix with fiber [35].

For this reason, untreated jute and glass fiber reinforced PCL composites displayed maximum WA that is $10.4 \%$. Besides, silane and alkali treatment enhanced jute fiber roughness topography and improved aspect ratio influenced in better fiber-matrix interfacial adhesion, including air-filled voids and pore filled up throughout the preparation of composite trend to lower water uptake. Moreover, glass fiber matt is highly hydrophobic that limits the moisture consumption between glass and jute fiber due to high toughness nature of the PCL matrix [22] [43]. After conducting WA, we observed the common tendency of composites showing significant changes in weight with extent immersion time as well as consuming excess moisture at the beginning of immersion until achieved a stable condition.

\subsection{Thickness Swelling (TS)}

Thickness swelling behavior of both treated and untreated optimized woven jute and glass fiber reinforced PCL composites exhibited in Figure 7.

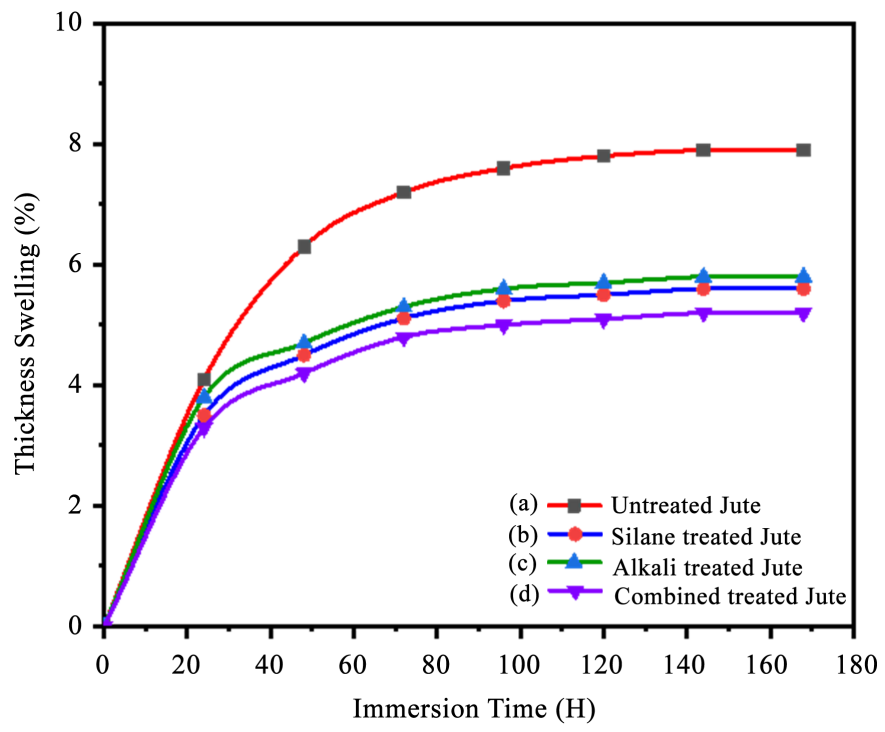

Figure 7. Thickness swelling behavior of treated and untreated woven jute and glass fiber reinforced PCL optimised composites. 
TS of composite has been arising predominantly due to the vulnerability of lignocellulosic fiber around the surface of composite because the amount of lingo cellulosic fiber varies with distinct moisture material [44]. The hydrophilic properties of lingo cellulosic substances with medium called capillary action get the consumption of water once the specimens saturated in water consuming the fiber resulting in changing the dimensional stability of the composite [42]. Figure 7 demonstrated that, the untreated optimized composites $R_{2}$ showing maximum results due to this reason among the optimized experimental group, which is around $7.9 \%$. Which is also an indication of low interfacial adhesion, micro air-filled void space, and pores appear in the composite that uptake the water inside those micro-voids and pores take part in changing dimensional stability with reversible and irreversible swelling of the composites [45]. Besides, the lowest TS result exhibiting the combined treated optimized sample $\mathrm{C}_{2}$ after 180 hours of immersion, which is respectively $12.06 \%$ lower than alkali-treated optimized sample $A_{2}$ and $8.92 \%$ for silane treated optimized sample $S_{2}$ attributed to comparatively better reducing the hydroxyl $(\mathrm{OH})$ group responsible for water uptake with chemical treatment [46]. At the beginning of immersion, the untreated composites incessantly uptakes more water and showing exceeding TS change than the treated reinforced composites. In addition, silane treatment, hydrogen $(\mathrm{H})$, and a covalent bond formed with polymer matrix resulting in enhanced fiber-matrix adhesion. It summarized from Figure 7, combined treated woven jute and glass fiber reinforced composite exhibited the lowest result, whereas silane and alkali-treated jute and glass fiber reinforced composite showing moderate result over untreated composite, which recorded the highest score in the optimized experimental group.

\subsection{Thermogravimetric Analysis of Composite}

The Thermogravimetric Analysis (TGA) outcomes affirmed that chemical treatments of woven jute fabric in jute and glass fiber reinforced PCL composites raised the operation of degradation resistance for these optimized processing composites, as exhibited in Figure 8.

Thermal stability is an essential property of fiber-reinforced composites [47]. Untreated composite decomposed in two-stage and started decomposing at lower temperatures compared to treated composite corresponding optimized samples. As demonstrated in Figure 8, both WL \% and DWL\% graph. Untreated jute initiated the first degradation step around $250^{\circ} \mathrm{C}$, and the second stage starts from $449^{\circ} \mathrm{C}$, which proceeded to accomplish decomposition around $520^{\circ} \mathrm{C}$. Alkali-treated composite overcomes this tendency and degradation completed in a single step due to the removal of hemicellulose as well as increase, and decrease of PCL reinforced molecular mass comparatively affects the thermal degradation process of the composites [48]. Besides, chemically treated woven jute and glass fiber reinforced PCL composites exhibiting improved thermal stability and enhanced the degradation of the composite over untreated composites. The thermal decomposition starts for alkali-treated composite from $302.5^{\circ} \mathrm{C}$ following 

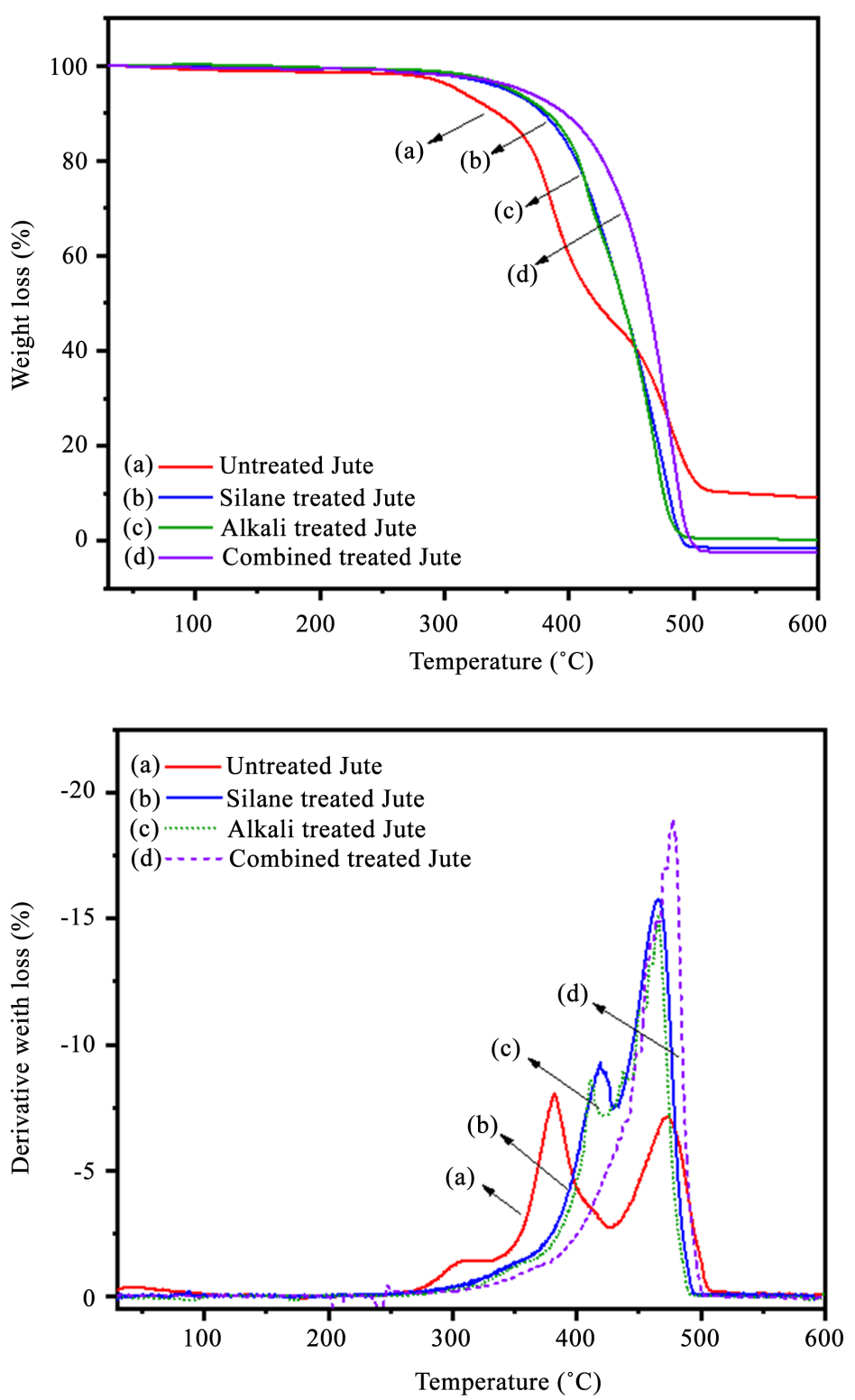

Figure 8. Thermal stability of treated \& untreated woven jute and glass fiber reinforced PCL composites.

reached to the ultimate stage near about $500.8^{\circ} \mathrm{C}$. As demonstrated, combined treated nonwoven jute and glass fiber reinforced PCL composite exhibited bit enhanced thermal stability compared to silane and alkali-treated composite, which is an indication elimination of natural hydrolyzed elements that decompose before that lignin and cellulose [49]. Moreover, decomposition of jute fiber can describe by heat range between $25^{\circ} \mathrm{C}-150^{\circ} \mathrm{C}$ composites weight loss indicated because of water volatilization, the second peak allocating between $190^{\circ} \mathrm{C}$ $300^{\circ} \mathrm{C}$, indicating the degradation of hemicellulose, the third peak showing between $300^{\circ} \mathrm{C}-360^{\circ} \mathrm{C}$ attributed to the degradation of cellulose. Lignin degradation takes place between $280^{\circ} \mathrm{C}-500^{\circ} \mathrm{C}$ [28] [50]. Moreover, a detailed decomposition process of selective processing conditions is enlisted in Table 3. 


\subsection{Composites Morphology Analysis}

Surface morphology of woven jute and glass fiber reinforced PCL composites obtained from tensile fracture is displayed in Figure 9.

Figure 9(a) showing SEM images of nonwoven glass fibers in $2 \mu \mathrm{m}$ range, whereas that Figure 9(b) showing the close look of glass fibers in $10 \mu \mathrm{m}$. SEM morphology of Figure 9(c) exhibiting the cross-sectional view of silane treated unidirectional woven jute attributed to the stiffness of composites.

That is an indication that PCL dispersed adequately into the surface of jute fibers without compromising essential distinctness, leading to improved ductility and stiffness of composites [4]. Figure 9(d) exhibiting empty hole or void content in the surface of untreated optimized sample. These voids take place during fabrication that likely causes detrimental effects in the mechanical properties of composites, which also responsible for excessive moisture absorption [2]. The
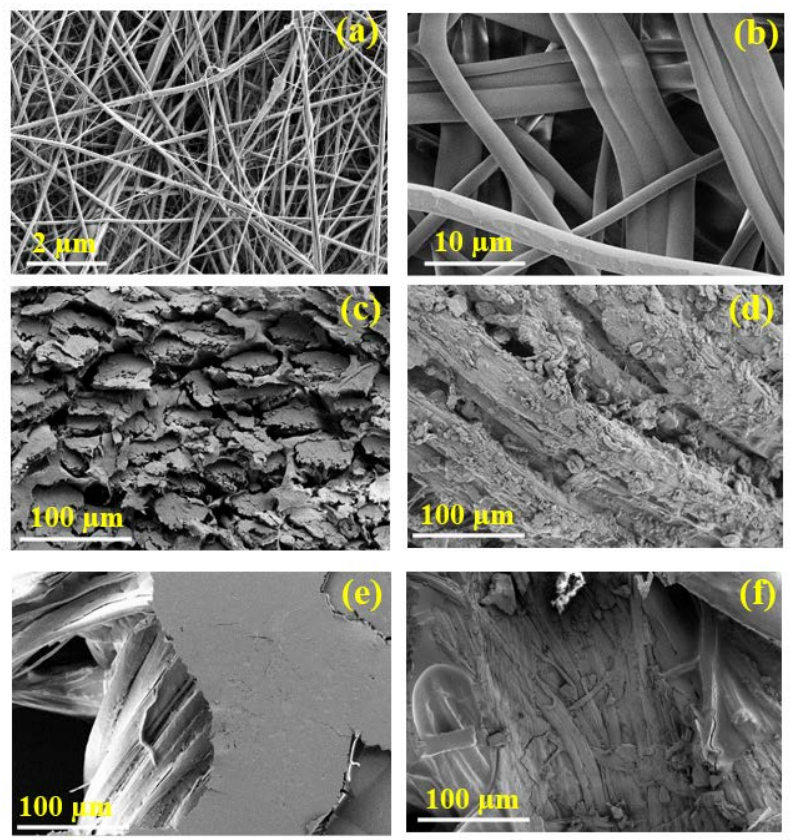

Figure 9. SEM morphology of woven jute and glass fiber reinforced PCL composites at different magnification range.

Table 3. Thermal decomposition values of optimized woven jute and glass fiber reinforced PCL composites derived from Figure 8.

\begin{tabular}{cccccccc}
\hline \multirow{2}{*}{$\begin{array}{c}\text { Sample } \\
\text { name }\end{array}$} & $\begin{array}{c}1^{\text {st }} \text { stage } \\
30^{\circ} \mathrm{C}-100^{\circ} \mathrm{C} \\
\mathrm{W}_{\text {loss }}(\%)\end{array}$ & \multicolumn{2}{c}{$2^{\text {nd }}$ Stage } & \multicolumn{2}{c}{$3^{\text {rd }}$ stage } & $\begin{array}{c}4^{\text {th }} \text { stage } \\
498^{\circ} \mathrm{C}-600^{\circ} \mathrm{C}\end{array}$ & $\begin{array}{c}\text { Residual } \\
\text { weight } \%\end{array}$ \\
\hline $\mathrm{R}_{2}$ & 0.851 & $100-269$ & 1.94 & $269-518$ & 89.55 & 90.88 & 0.10 \\
$\mathrm{~S}_{2}$ & 0.403 & $100-312$ & 2.10 & $312-500$ & 99.09 & 100 & 0.29 \\
$\mathrm{~A}_{2}$ & 0.243 & $100-312$ & 1.77 & $312-498$ & 99.31 & 99.67 & 0.37 \\
$\mathrm{C}_{2}$ & 0.425 & $100-312$ & 2.29 & $312-511$ & 100 & 100 & 0.44 \\
\hline
\end{tabular}

Where $\mathrm{T}_{\text {range }}$ stands for temperature range and $\mathrm{W}_{\text {loss }}$ for weight loss. 
fractured surface of Figure 9(e) clearly demonstrates lower adhesion within fiber and PCL matrix, where fiber pull-out and debonding phenomena can observe. Figure 9(f) revealed that due to chemical treatment, PCL grafted thoroughly into the surface of jute fibers without any destruction. Alkali-silane combined treatment promotes removing hemicellulose content that is responsible for strong hydrophobic character of natural fibers thus improved fiber-matrix adhesion formed with fibrillate tendency [5]. Besides, microcracks observed in specific figure evidence of higher amount of load efficiently transferred by extending fiber-matrix interface, respectively.

For this reason, thermal stability and moisture resistance capabilities of composites significantly enhanced [3] [19].

\section{Conclusion}

In this experiment, woven jute and glass fiber reinforced PCL composites were fabricated using the hot-pressing method where jute used as a sandwich with upper and lower nonwoven glass fiber sheets using PCL as a matrix. The experiment was conducted to distinguish the effects of chemical treatment and detect hot pressing preeminent parameters such as hot-pressing temperature, pressure, and time. As demonstrated, alkali and silane combined treated optimized sample $\mathrm{C}_{2}$ exhibited the highest tensile strength. Surface chemistry was analyzed using FTIR, and observed fiber modification occurred in every treatment of woven jute fiber. Mechanical properties of composite influenced by interfacial adhesion between fiber and matrix as substantiated after observing morphological structures with a scanning electron microscope (SEM). Mechanical properties, tensile strength resulting in $48.38 \%$ improvement in tensile strength in alkali-silane combined treated composite over untreated optimized composites. Better fiber-matrix interfacial adhesion attributes accelerated thermal stability of combined treated composite compared to alkali, silane, and untreated commercial woven jute-glass fibers reinforced PCL composites. Eventually, a $165^{\circ} \mathrm{C}$ hot pressing temperature, $7 \mathrm{MPa}$ pressure, and 9 minutes of heat pressing with 6 minutes curing can consider as a suitable parameter for this composite to produce outstanding lightweight woven jute and glass fiber reinforced PCL composites. Besides, alkali-silane combined chemical treatment revealed maximum effective outcomes from the experimental group.

\section{Acknowledgements}

The authors gratefully acknowledge the Hangzhou mi ke chemical instrument co. Ltd and Xinxiang filter material co. Ltd for providing experimental materials.

\section{Conflicts of Interest}

The authors declare no conflict of interest in financially or any other manner.

\section{References}

[1] Arbelaiz, A., Fernández, B., Valea, A. and Mondragon, I. (2006) Mechanical Proper- 
ties of Short Flax Fibre Bundle/Poly ( $\varepsilon$-Caprolactone) Composites: Influence of Matrix Modification and Fibre Content. Carbohydrate Polymers, 64, 224-232. https://doi.org/10.1016/j.carbpol.2005.11.030

[2] Sarasini, F., Tirillò, J., Puglia, D., Dominici, F., Santulli, C., Boimau, K., et al. (2017) Biodegradable Polycaprolactone-Based Composites Reinforced with Ramie and Borassus Fibres. Composite Structures, 167, 20-29. https://doi.org/10.1016/j.compstruct.2017.01.071

[3] Rafiquzzaman, M., Islam, M., Rahman, H., Talukdar, S. and Hasan, N. (2016) Mechanical Property Evaluation of Glass-Jute Fiber Reinforced Polymer Composites. Polymers for Advanced Technologies, 27, 1308-1316. https://doi.org/10.1002/pat.3798

[4] Cheung, H.-Y., Ho, M.-P., Lau, K.-T., Cardona, F. and Hui, D. (2009) Natural Fibre-Reinforced Composites for Bioengineering and Environmental Engineering Applications. Composites Part B: Engineering, 40, 655-663. https://doi.org/10.1016/j.compositesb.2009.04.014

[5] Chen, Y., Chiparus, O., Sun, L., Negulescu, I., Parikh, D.V. and Calamari, T.A. (2005) Natural Fibers for Automotive Nonwoven Composites. Journal of Industrial Textiles, 35, 47-62. https://doi.org/10.1177/1528083705053392

[6] Plackett, D., Andersen, T.L., Pedersen, W.B. and Nielsen, L. (2003) Biodegradable Composites Based on L-Polylactide and Jute Fibres. Composites Science and Technology, 63, 1287-1296. https://doi.org/10.1016/S0266-3538(03)00100-3

[7] Hassan, M.L. (2003) Recycling of Jute Textile in Phenol Formaldehyde-Jute Composites. Journal of Applied Polymer Science, 90, 3588-3593.

https://doi.org/10.1002/app.13066

[8] Luckachan, G.E. and Pillai, C. (2011) Biodegradable Polymers-A Review on Recent Trends and Emerging Perspectives. Journal of Polymers and the Environment, 19, 637-676. https://doi.org/10.1007/s10924-011-0317-1

[9] Dong, Y., Ghataura, A., Takagi, H., Haroosh, H.J., Nakagaito, A.N. and Lau, K.-T. (2014) Polylactic Acid (PLA) Biocomposites Reinforced with Coir Fibres: Evaluation of Mechanical Performance and Multifunctional Properties. Composites Part A: Applied Science and Manufacturing, 63, 76-84. https://doi.org/10.1016/j.compositesa.2014.04.003

[10] Xia, X., Liu, W., Zhou, L., Hua, Z., Liu, H. and He, S. (2016) Modification of Flax Fiber Surface and Its Compatibilization in Polylactic Acid/Flax Composites. Iranian Polymer Journal, 25, 25-35. https://doi.org/10.1007/s13726-015-0395-3

[11] Orue, A., Jauregi, A., Peña-Rodriguez, C., Labidi, J., Eceiza, A. and Arbelaiz, A. (2015) The Effect of Surface Modifications on Sisal Fiber Properties and Sisal/Poly (Lactic Acid) Interface Adhesion. Composites Part B: Engineering, 73, 132-138. https://doi.org/10.1016/j.compositesb.2014.12.022

[12] Luo, S. and Netravali, A. (1999) Interfacial and Mechanical Properties of Environment-Friendly "Green" Composites Made from Pineapple Fibers and Poly (Hydroxybutyrate-Co-Valerate) Resin. Journal of Materials Science, 34, 3709-3719. https://doi.org/10.1023/A:1004659507231

[13] Debeli, D.K. (2019) Diammonium Phosphate-Modified Ramie Fiber Reinforced Polylactic Acid Composite and Its Performances on Interfacial, Thermal, and Mechanical Properties. Journal of Natural Fibers, 16, 342-356. https://doi.org/10.1080/15440478.2017.1423255

[14] Sawpan, M.A., Pickering, K.L. and Fernyhough, A. (2012) Flexural Properties of Hemp Fibre Reinforced Polylactide and Unsaturated Polyester Composites. Com- 
posites Part A: Applied Science and Manufacturing, 43, 519-526. https://doi.org/10.1016/j.compositesa.2011.11.021

[15] Huda, M.S., Drzal, L.T., Mohanty, A.K. and Misra, M. (2008) Effect of Fiber Surface-Treatments on the Properties of Laminated Biocomposites from Poly (Lactic Acid) (PLA) and Kenaf Fibers. Composites Science and Technology, 68, 424-432. https://doi.org/10.1016/j.compscitech.2007.06.022

[16] Wang, H., Memon, H., Hassan, E.A.M., Sohag Miah, Md. and Arshad Ali, Md. (2019) Effect of Jute Fiber Modification on Mechanical Properties of Jute Fiber Composite. Materials, 12, Article No. 1226. https://doi.org/10.3390/ma12081226

[17] Palanikumar, K., Ramesh, M. and Hemachandra Reddy, K. (2016) Experimental Investigation on the Mechanical Properties of Green Hybrid Sisal and Glass Fiber Reinforced Polymer Composites. Journal of Natural Fibers, 13, 321-331. https://doi.org/10.1080/15440478.2015.1029192

[18] Khan, R.A., Sharmin, N., Khan, M.A., Das, A.K., Dey, K., Saha, S., et al. (2011) Comparative Studies of Mechanical and Interfacial Properties between Jute Fiber/PVC and E-Glass Fiber/PVC Composites. Polymer-Plastics Technology and Engineering, 50, 153-159. https://doi.org/10.1080/03602559.2010.531422

[19] Jarukumjorn, K. and Suppakarn, N. (2009) Effect of Glass Fiber Hybridization on Properties of Sisal Fiber-Polypropylene Composites. Composites Part B: Engineering, 40, 623-627. https://doi.org/10.1016/j.compositesb.2009.04.007

[20] Muthuvel, M., Ranganath, G. and Janarthanan, K. (2013) Characterization Study of Jute and Glass Fiber Reinforced Hybrid Composite Material. International Journal of Engineering Research \& Technology, 2, 335-344.

[21] Velmurugan, R. and Manikandan, V. (2007) Mechanical Properties of Palmyra/Glass Fiber Hybrid Composites. Composites Part A: Applied Science and Manufacturing, 38, 2216-2226. https://doi.org/10.1016/j.compositesa.2007.06.006

[22] Huq, T., Khan, A., Noor, N., Saha, M., Khan, R.A. and Khan, M.A. (2010) Comparative Studies on the Mechanical, Degradation and Interfacial Properties between Jute and E-Glass Fiber-Reinforced PET Composites. Polymer-Plastics Technology and Engineering, 49, 1128-1135. https://doi.org/10.1080/03602559.2010.496396

[23] Boopalan, M., Niranjanaa, M. and Umapathy, M. (2013) Study on the Mechanical Properties and Thermal Properties of Jute and Banana Fiber Reinforced Epoxy Hybrid Composites. Composites Part B: Engineering, 51, 54-57.

https://doi.org/10.1016/j.compositesb.2013.02.033

[24] Gowda, T.M., Naidu, A. and Chhaya, R. (1999) Some Mechanical Properties of Untreated Jute Fabric-Reinforced Polyester Composites. Composites Part A: applied science and manufacturing, 30, 277-284.

https://doi.org/10.1016/S1359-835X(98)00157-2

[25] George, J., Sreekala, M. and Thomas, S. (2001) A Review on Interface Modification and Characterization of Natural Fiber Reinforced Plastic Composites. Polymer Engineering \& Science, 41, 1471-1485. https://doi.org/10.1002/pen.10846

[26] Nam, T.H., Ogihara, S., Tung, N.H. and Kobayashi, S. (2011) Effect of Alkali Treatment on Interfacial and Mechanical Properties of Coir Fiber Reinforced Poly (Butylene succinate) Biodegradable Composites. Composites Part B: Engineering, 42, 1648-1656. https://doi.org/10.1016/j.compositesb.2011.04.001

[27] Zhang, L., Sun, Z., Liang, D., Lin, J. and Xiao, W. (2017) Preparation and Performance Evaluation of PLA/Coir Fibre Biocomposites. BioResources, 12, 7349-7362.

[28] Goriparthi, B.K., Suman, K. and Rao, N.M. (2012) Effect of Fiber Surface Treat- 
ments on Mechanical and Abrasive Wear Performance of Polylactide/Jute Composites. Composites Part A: Applied Science and Manufacturing, 43, 1800-1808. https://doi.org/10.1016/j.compositesa.2012.05.007

[29] Gassan, J. and Bledzki, A.K. (1997) Effect of Moisture Content on the Properties of Silanized Jute-Epoxy Composites. Polymer Composites, 18, 179-184. https://doi.org/10.1002/pc.10272

[30] Wang, X., Wang, L., Ji, W., Hao, Q., Zhang, G. and Meng, Q. (2019) Characterization of KH-560-Modified Jute Fabric/Epoxy Laminated Composites: Surface Structure, and Thermal and Mechanical Properties. Polymers, 11, Article No. 769. https://doi.org/10.3390/polym11050769

[31] Debeli, D.K., Qin, Z. and Guo, J. (2018) Study on the Pre-Treatment, Physical and Chemical Properties of Ramie Fibers Reinforced Poly (Lactic Acid) (PLA) Biocomposite. Journal of Natural Fibers, 15, 596-610. https://doi.org/10.1080/15440478.2017.1349711

[32] John, M.J., Francis, B., Varughese, K.T. and Thomas, S. (2008) Effect of Chemical Modification on Properties of Hybrid Fiber Biocomposites. Composites Part A: Applied Science and Manufacturing, 39, 352-363. https://doi.org/10.1016/j.compositesa.2007.10.002

[33] Beijing FRP Research Institute (2005) Fiber-Reinforced Plastics Composites-Determination of Tensile Properties. GB/T 1447-2005, General Administration of Quality Supervision, Inspection and Quarantine of the People Republic of China, China National Standardization Administration Committee, Beijing. https://www.chinesestandard.net/PDF/English.aspx/GBT1447-2005.

[34] Baillie, C. (2004) Green Composites: Polymer Composites and the Environment. CRC Press, Boca Raton.

[35] Saw, S.K., Akhtar, K., Yadav, N. and Singh, A.K. (2014) Hybrid Composites Made from Jute/Coir Fibers: Water Absorption, Thickness Swelling, Density, Morphology, and Mechanical Properties. Journal of Natural Fibers, 11, 39-53. https://doi.org/10.1080/15440478.2013.825067

[36] Gañán, P., Zuluaga, R., Restrepo, A., Labidi, J. and Mondragon, I. (2008) Plantain Fibre Bundles Isolated from Colombian Agro-Industrial Residues. Bioresource Technology, 99, 486-491. https://doi.org/10.1016/j.biortech.2007.01.012

[37] Haque, M.M., Hasan, M., Saiful Islam, Md. and Ershad Ali, Md. (2009) Physico-Mechanical Properties of Chemically Treated Palm and Coir Fiber Reinforced Polypropylene Composites. Bioresource Technology, 100, 4903-4906. https://doi.org/10.1016/j.biortech.2009.04.072

[38] Hossain, M.K., Dewan, M.W., Hosur, M. and Jeelani, S. (2011) Mechanical Performances of Surface Modified Jute Fiber Reinforced Biopol Nanophased Green Composites. Composites Part B: Engineering, 42, 1701-1707.

https://doi.org/10.1016/j.compositesb.2011.03.010

[39] Saha, P., Manna, S., Chowdhury, S.R., Sen, R., Roy, D. and Adhikari, B. (2010) Enhancement of Tensile Strength of Lignocellulosic Jute Fibers by Alkali-Steam Treatment. Bioresource Technology, 101, 3182-3187.

https://doi.org/10.1016/j.biortech.2009.12.010

[40] Khan, M.A. and M.M. Hassan (2006) Effect of $\gamma$-Aminopropyl Trimethoxy Silane on the Performance of Jute-Polycarbonate Composites. Journal of Applied Polymer Science, 100, 4142-4154. https://doi.org/10.1002/app.23441

[41] Hong, C., Hwang, I., Kim, N., Park, D.H., Hwang, B.S. and Nah, C. (2008) Mechanical Properties of Silanized Jute-Polypropylene Composites. Journal of Industrial 
and Engineering Chemistry, 14, 71-76. https://doi.org/10.1016/j.jiec.2007.07.002

[42] Jawaid, M., Abdul Khalil, H.P.S., Noorunnisa Khanam, P. and Abu Bakar, A. (2011) Hybrid Composites Made from Oil Palm Empty Fruit Bunches/Jute Fibres: Water Absorption, Thickness Swelling and Density Behaviours. Journal of Polymers and the Environment, 19, 106-109. https://doi.org/10.1007/s10924-010-0203-2

[43] Munoz, E. and García-Manrique, J.A. (2015) Water Absorption Behaviour and Its Effect on the Mechanical Properties of Flax Fibre Reinforced Bioepoxy Composites. International Journal of Polymer Science, 2015, Article ID: 390275. https://doi.org/10.1155/2015/390275

[44] Khalil, H.A., Issam, A.M., Ahmad Shakri, M.T., Suriani, R. and Awang, A.Y. (2007) Conventional Agro-Composites from Chemically Modified Fibres. Industrial Crops and Products, 26, 315-323. https://doi.org/10.1016/j.indcrop.2007.03.010

[45] Sari, P., Spatenka, P., Jenikova, Z., Grohens, Y. and Thomas, S. (2015) New Type of Thermoplastic Bio Composite: Nature of the Interface on the Ultimate Properties and Water Absorption. RSC Advances, 5, 97536-97546.

https://doi.org/10.1039/C5RA16311K

[46] Mohammed, L., Ansari, M.N.M., Pua, G., Jawaid, M. and Saiful Islam, M. (2015) A Review on Natural Fiber Reinforced Polymer Composite and Its Applications. International Journal of Polymer Science, 2015, Article: ID 243947. https://doi.org/10.1155/2015/243947

[47] Farhadinejad, Z., Ehsani, M., Khosravian, B. and Ebrahimi, G. (2012) Study of Thermal Properties of Wood Plastic Composite Reinforced with Cellulose Micro Fibril and Nano Inorganic Fiber Filler. European Journal of Wood and Wood Products, 70, 823-828. https://doi.org/10.1007/s00107-012-0630-y

[48] de Oliveira Aguiar, V. and de Fatima Vieira Marques, M. (2016) Composites of Polycaprolactone with Cellulose Fibers: Morphological and Mechanical Evaluation. Macromolecular Symposia, 367, 101-112. https://doi.org/10.1002/masy.201500142

[49] Rosa, M.F., Chiou, B.-S., Medeiros, E.S., Wood, D.F., Williams, T.G., Mattoso, L.H.C., et al. (2009) Effect of Fiber Treatments on Tensile and Thermal Properties of Starch/Ethylene Vinyl Alcohol Copolymers/Coir Biocomposites. Bioresource Technology, 100, 5196-5202. https://doi.org/10.1016/j.biortech.2009.03.085

[50] Kabir, M., Wang, H., Lau, K.T., Cardona, F. and Aravinthan, T. (2012) Mechanical Properties of Chemically-Treated Hemp Fibre Reinforced Sandwich Composites. Composites Part B: Engineering, 43, 159-169.

https://doi.org/10.1016/j.compositesb.2011.06.003

\section{List of Abbreviations}

$\mathrm{PCL}=$ Polycaprolactone, $\mathrm{Wt} \%=$ weight $\% . \mathrm{DCM}=$ Dichloromethane,${ }^{\circ} \mathrm{C}=\mathrm{Cel}-$ sius, $\mathrm{GPa}=$ Giga pascal, $\mathrm{MPa}=$ Mega pascal, $\mathrm{Kj} / \mathrm{m}^{2}=$ Kilojoule/square meter. 